\title{
Colchicine Intoxication in Children: Four Case Reports
}

\author{
Ayşenur P. KISAARSLAN, ${ }^{1}$ Sibel YEL, ${ }^{2}$ Kenan YILMAZ,, 2 Başak Nur AKYILDIZ, ${ }^{3}$ Ruhan DÜşÜNSEL, \\ Zübeyde GÜNDÜZ, ${ }^{1}$ Hakan POYRAZOĞLU, ${ }^{1}$ Gül YÜCEL, ${ }^{4}$ Feride GÜVEN ${ }^{4}$ \\ ${ }^{1}$ Department of Pediatric Rheumatology, Medical Faculty of Erciyes University, Kayseri, Turkey \\ ${ }^{2}$ Department of Pediatric Neuphrology, Medical Faculty of Erciyes University, Kayseri, Turkey \\ ${ }^{3}$ Department of Pediatric Intensive Care Unit, Medical Faculty of Erciyes University, Kayseri, Turkey \\ ${ }^{4}$ Department of Pediatric, Medical Faculty of Erciyes University, Kayseri, Turkey
}

\begin{abstract}
Colchicine is a natural alkaloid which is derived from the colchium autumnale plant. It is used in the treatment of familial Mediterranean fever, amyloidosis, gout, Behçet's disease, and inflammatory bowel disease. In this article, we present four colchicine intoxication cases who were admitted to our clinic last year. While two patients ingested colchicine accidentally, other two took it for attempted suicide. First patient's clinical signs were gastroenteritis, fever, and alopecia. This patient developed renal, hepatic dysfunction, and rebound leucocytosis. Patient was given support treatment and discharged. Second patient's physical examination was normal except for tachycardia. Twenty hours after taking the medication, patient developed leucocytosis. The patient was performed plasmapheresis and leukapheresis. Thirty-nine hours after intake, patient developed sudden cardiac arrest and died. Third patient's clinical signs were gastroenteritis, fever, and alopecia. Patient developed hepatic dysfunction and rebound leucocytosis. Support treatment was given and patient was discharged. Last patient had no clinical sign or laboratory finding and was discharged. Doctors and other healthcare employees should be alert for possible colchicine intoxication symptoms. Early detection of overdose symptoms is significant in terms of treatment success.

Keywords: Colchicine intoxication; early diagnose; findings.
\end{abstract}

Colchicine which is derived from the colchium autumnale plant is a naturally occurring alkaloid. It is used in the treatment of familial Mediterranean fever (FMF), amyloidosis, gout, Behçet's disease, and inflammatory bowel disease. It is rapidly absorbed from the gastrointestinal tract after ingestion. Colchicine poisoning is very rare, but serious complications may occur following ingestion of colchicine either accidentally or as a result of attempted suicide. Overdose with colchicine constitutes a toxicological emergency and rapid intervention is required. ${ }^{1}$

Herein, we present four patients with colchicine overdose who were admitted to our hospital last year.

\section{CASE REPORT}

Case 1- A 15-year-old girl was admitted with fever, abdominal pain and vomiting. Prerenal acute renal failure, metabolic acidosis and pancytopenia were detected (Table 1). Intravenous fluid and sodium bicarbonate infusion were started. The patient was conscious. The lumbar puncture was normal. Bone marrow aspiration was administered for pancytopenia. Ketamine which is a sedative and analgesic agent was used before aspiration. After ketamine sedation effect, the patient said that she ingested twenty of her grandfather's colchicine tablets three days ago to commit suicide. Her treatment was supportive. On the seventh day, rebound leukocytosis and

Received: April 08, 2014 Accepted: May 13, 2014 Published online: February 05, 2015

Correspondence: Ayşenur P. Kısaarslan, M.D. Erciyes Üniversitesi Tıp Fakültesi Pediatrik Romatoloji Bilim Dalı, 38039 Talas, Kayseri, Turkey.

Tel: +90 352 - 2076666 e-mail: aysenurkisaarslan@hotmail.com

○2015 Turkish League Against Rheumatism. All rights reserved. 
thrombocytosis developed. Twenty days after ingestion, patient regained normal hematologic and biochemistry levels. She was discharged in a stable condition. However, the patient continued to suffer from alopecia throughout the next two months.

Case 2- A 3.5-year-old girl who ingested 17 of her mother's colchicine tablets was admitted to a secondary hospital three hours after ingestion. Physical examination was unremarkable. Gastric lavage and activated charcoal were administered in the emergency room. Twenty hours after ingestion, the patient developed leukocytosis, rhabdomyolysis and elevated hepatic functions. She was transferred to a tertiary hospital. In the intensive care unit, physical examination was normal except for tachycardia. Her laboratory findings are shown in Table 1. Plasmapheresis and leucopheresis were performed. Tachycardia continued throughout. Nineteen hours after admission, patient suffered cardiac arrest and died.

Case 3- A five-year-old girl presented to our emergency department for fever and gastroenteritis which started two days ago, and

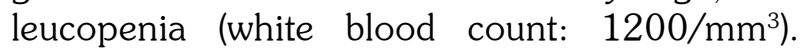
Patient's medical history revealed that she had FMF which was first diagnosed one year ago and for which she took colchicine $1 \mathrm{mg} /$ day. Physical examination was normal. Laboratory findings included leukocytosis, elevated liver function, hypomagnesemia, and hyponatremia

Table 1. Patients' physical and laboratory findings

\begin{tabular}{|c|c|c|c|c|}
\hline & Case 1 & Case 2 & Case 3 & Case 4 \\
\hline Age/gender (years) & $15 / F$ & $3.5 / \mathrm{F}$ & $5 / \mathrm{F}$ & $15 / F$ \\
\hline Time after ingestion & 3 days & 3 hours & $?$ & 3 hours \\
\hline Hospitalization time (PICU/T) & $3 / 19$ & $2 / 2$ & $0 / 9$ & $1 / 5$ \\
\hline Total colchicine dose (mg/kg dose) & $10 \mathrm{mg}(0.2)$ & $8 \mathrm{mg}(0.60)$ & $?$ & $5 \mathrm{mg}(0.11)$ \\
\hline Reason & Suicide & Accidental & Accidental & Suicide \\
\hline Clinical findings & $\begin{array}{l}\text { Gastroenteritis, fever, } \\
\text { consciousness, alopecia }\end{array}$ & $\begin{array}{l}\text { Tachycardia, sudden } \\
\text { cardiac arrest }\end{array}$ & $\begin{array}{l}\text { Gastroenteritis, } \\
\text { fever, alopecia }\end{array}$ & - \\
\hline Hemoglobin (gr/dL) & $9.5-8.5$ & 14.5 & 11 & 12.1 \\
\hline White blood cell $\left(\mathrm{mm}^{3}\right)$ & $1.760-38.230$ & 56.490 & 44.470 & 8.690 \\
\hline Platelet $\left(\mathrm{mm}^{3}\right)$ & $21.000-713.000$ & 327.000 & 281.000 & 269.000 \\
\hline Glucose (mg/dL) & 116 & 96 & 80 & 100 \\
\hline Blood urea nitrogen (mg/dL) & 61 & 23 & 8 & 11 \\
\hline Creatinine (mg/dL) & 2.5 & 0.6 & 0.4 & 0.6 \\
\hline Sodium (mEq/L) & 134 & 136 & 128 & 140 \\
\hline Potassium (mEq/L) & 4.5 & 3.6 & 4.0 & 4.1 \\
\hline Chloride (mEq/L) & 108 & 105 & 94 & 106 \\
\hline Aspartate transaminase (IU/L) & 472 & 297 & 77 & 30 \\
\hline Alanine transaminase (IU/L) & 84 & 41 & 209 & 14 \\
\hline Total protein $(\mathrm{gr} / \mathrm{dL})$ & 6.2 & 7 & 5.6 & 7.6 \\
\hline Albumin (gr/dL) & 3.9 & 3.9 & 2.8 & 4.4 \\
\hline Uric acid (mg/dL) & 8.0 & 7.3 & 4.2 & 3 \\
\hline Calcium (mg/dL) & 7.9 & 6.7 & 8.7 & 9.3 \\
\hline Phosphorus (mg/dL) & 2.5 & 3.6 & 3.9 & 3.1 \\
\hline Alkaline phosphatase (IU/L) & 84 & 1503 & 151 & 88 \\
\hline Magnesium (mg/dL) & 0.57 & 0.8 & 0.6 & 0.8 \\
\hline Creatine kinase (IU/L) & 2.016 & 4.268 & 136 & 98 \\
\hline Creatine kinase muscle-brain fraction (IU/L) & 85.7 & 517 & 28.4 & 33.5 \\
\hline Lactate dehydrogenase (IU/L) & 963 & 2.939 & 1.705 & 360 \\
\hline Lactate $(\mathrm{mmol} / \mathrm{L})$ & ? & 4.99 & ? & ? \\
\hline Hematuria & - & ? & - & - \\
\hline Proteinuria & + & ? & - & - \\
\hline Metabolic acidosis & + & - & - & - \\
\hline Prothrombin time & 11.1 & ? & 15.4 & 14.5 \\
\hline Partial thromboplastin time & 21.8 & ? & 21.2 & 22.2 \\
\hline International normalized ratio & 1.01 & ? & 1.34 & 1.27 \\
\hline D-dimer & 9.360 & $?$ & 1.860 & - \\
\hline Treatment & Supportive & $\begin{array}{c}\text { Supportive, } \\
\text { plasma-leucopheresis }\end{array}$ & Supportive & Supportive \\
\hline Outcome & Discharged & Died & Discharged & Discharged \\
\hline
\end{tabular}


(Table 1). Treatment was supportive. Alopecia started throughout the hospitalization. Patient was discharged on day 10 .

Case 4- A 15-year-old girl was admitted to the emergency unit for attempted suicide. She had ingested $5 \mathrm{mg}$ colchicine three hours prior to admission. She had a history of FMF, for which she had been on colchicine therapy $1 \mathrm{mg}$ daily for 12 years. Physical examination was unremarkable. In the emergency room, activated charcoal was administered and she was referred to the intensive care unit. Patient's physical and laboratory findings did not change on the first day and subsequent days (Table 1). She was hospitalized for four days and discharged on day five.

\section{DISCUSSION}

Colchicine is an active alkaloid that is extracted from colchium autumnale. It is used to prevent FMF attacks and amyloidosis in children. Furthermore, colchicine is used for gout, Behçet's disease and inflammatory bowel disease in adults. It is a safe drug in children with FMF. ${ }^{2}$ The drug is rapidly absorbed from the gastrointestinal tract after ingestion. It undergoes significant first pass hepatic metabolism. Subsequently, there is significant enterohepatic recirculation with $10-20 \%$ renal excretion. After absorption, colchicine is rapidly distributed to all tissues where it is heavily protein bound. ${ }^{3}$

Colchicine poisoning classically presents in three stages. ${ }^{1}$ The initial stage at $<24$ hours is characterized by gastrointestinal symptoms such as abdominal pain, nausea, vomiting, and diarrhea. Our first and third patients presented gastrointestinal symptoms. First patient ingested colchicine three days before being admitted to hospital. However, poisoning was not confirmed in third patient.

The second phase from two to seven days post ingestion is the most dangerous period. This phase is characterized by multi-organ failure, involving bone marrow suppression, kidney and liver failure, acute respiratory distress syndrome, arrhythmias, cardiovascular collapse, and neuromuscular involvement. First patient had phase two prerenal acute renal failure, metabolic acidosis, and pancytopenia. Third patient had hyponatremia, hepatic dysfunction, and hypomagnesemia. The most interesting patient in this group was patient two who did not have any symptoms except tachycardia. Although metabolic acidosis did not develop in this patient, she had severe leukocytosis on first day. Muscle enzymes (creatine kinase, creatine kinase musclebrain fraction, lactate dehydrogenase, and lactate) were very high. Patient suffered sudden cardiac arrest and died. Karacan et al. ${ }^{4}$ reported two patients with leukocytosis and elevated creatine kinase, aspartate aminotransferase, alanine aminotransferase, and prolongation of coagulation parameters 5-8 hours after colchicine ingestion. Their patient was admitted to hospital 30 hours after ingestion of an unknown amount of colchicine tablets. Patient's laboratory findings revealed elevated liver enzymes, i.e. creatine kinase, alkaline phosphatase, blood urea nitrogen, and creatinin. However, blood gas analysis was normal. Patient's leucocyte count was $49.900 / \mathrm{mm}^{3}$ and his cardiac functions were worse. Patient died three hours after admission. ${ }^{4}$ Our second patient had a very high leucocyte count, similarly. Early elevation of leukocyte count may predict poor prognosis. Following oral administration, colchicine rapidly and extensively diffuses into tissue. Although approximately $50 \%$ of circulating colchicine is bound to plasma proteins and the plasma half-life is short, colchicine is demonstrated in leukocytes nine days after its administration. ${ }^{5,6}$ Although we performed plasmapheresis and leucopheresis, our second patient died.

The third stage of intoxication is only seen in patients who recover from colchicine poisoning. It usually starts after day seven when there is resolution of organ failure, rebound leukocytosis and alopecia. Rebound leukocytosis and alopecia occurred in first and third patients in our study. They suffered from alopecia for approximately two months after colchicine ingestion.

No clinical or laboratory findings were present in our fourth patient. This patient was referred to the psychiatry department for attempted suicide. There are very different causes of colchicine exposure. Levsky et al. ${ }^{7}$ reported 79 cases of colchicine exposure. The most common causes of exposure were unintentional-therapeutic 
error (33\%), unintentional-general (28\%), and unintentional-suspected suicide (18\%). Medical outcomes included no effect (24\%) and major effect (3\%). ${ }^{7}$

Prognosis of colchicine poisoning is mainly associated with the dose of ingestion and the time of admission after ingestion. Reports on adults showed that if the colchicine dose is under $0.5 \mathrm{mg} / \mathrm{kg}$, minor toxicity developed and $100 \%$ of patients recovered. At a dose of $0.5-0.8 \mathrm{mg} / \mathrm{kg}$, major toxicity developed and the mortality rate was $10 \%$. At a dose $>0.8 \mathrm{mg} / \mathrm{kg}$, cardiogenic shock occurred in 72 hours and the mortality rate was $100 \% .^{8-10}$ The dose ingested by our patient who died was $0.6 \mathrm{mg} / \mathrm{kg}$. In the literature, a child who ingested $0.37 \mathrm{mg} / \mathrm{kg}$ colchicine was reported to have died. ${ }^{11}$

All patients suspected of colchicine intoxication should be managed according to the principles of intensive care, irrespective of the actual degree of poisoning. ${ }^{12}$ Colchicine is available as blistered tablet in our country. This situation is a risk factor for colchicine poisoning in children. Doctors and other healthcare employees should be alert for possible colchicine poisoning symptoms, and any overdose must be detected early for treatment success.

\section{Declaration of conflicting interests}

The authors declared no conflicts of interest with respect to the authorship and/or publication of this article.

\section{Funding}

The authors received no financial support for the research and/or authorship of this article.

\section{REFERENCES}

1. Karakaya ZY. Colchicine intoxication. In: Satar S, editor. Clinic toxicology in emergency. Adana: Nobel Company; 2009. p. 397-9.

2. Padeh S, Gerstein M, Berkun Y. Colchicine is a safe drug in children with familial Mediterranean fever. J Pediatr 2012;161:1142-6.

3. Iosfina I, Lan J, Chin C, Werb R, Levin A. Massive colchicine overdose with recovery. Case Rep Nephrol Urol 2012;2:20-4.

4. Karacan M, Olgun H, Ylldırım ZK, Karakelleoğlu C, Ceviz N. Colchicine poisoning in children: 7 case reports. J Curr Ped 2009;7:96-100.

5. Donovan JW. Nonsteroidal anti-inflamatory drugs and colchicine. In: Haddad LM, Shannon M, Winchester $\mathrm{JE}$, editors. Clinical management of poisoning and drug overdose. 3rd ed. Philadelphia: W.B. Saunders Company; 1999. p. 687-99.

6. Milne ST, Meek PD. Fatal colchicine overdose: report of a case and review of the literature. Am J Emerg Med 1998;16:603-8.

7. Levsky ME, Miller MA, Masneri DA, Borys D. Colchicine exposures: the Texas experience. South Med J 2008;101:480-3.

8. Bismuth C, Baud F, Dally S. Standardized prognosis evaluation in acute toxicology its benefit in colchicine, paraquat and digitalis poisonings. $\mathrm{J}$ Toxicol Clin Exp 1986;6:33-8.

9. Weakley-Jones B, Gerber JE, Biggs G. Colchicine poisoning: case report of two homicides. Am J Forensic Med Pathol 2001;22:203-6.

10. Murray SS, Kramlinger KG, McMichan JC, Mohr DN. Acute toxicity after excessive ingestion of colchicine. Mayo Clin Proc 1983;58:528-32.

11. Atas B, Caksen H, Tuncer O, Kirimi E, Akgün C, Odabaş D. Four children with colchicine poisoning. Hum Exp Toxicol 2004;23:353-6.

12. Biçer S, Soysal DD, Ctak A, Uçsel R, Karaböcüoğlu M, Uzel N. Acute colchicine intoxication in a child: a case report. Pediatr Emerg Care 2007;23:314-7. 